\title{
Lake Suigetsu 2006 Varved Sediment Core Project
}

Takeshi Nakagawa ${ }^{1}$ and Suigetsu 2006 Project Members ${ }^{2}$

'School of Geography, Politics and Sociology, Newcastle University, Newcastle upon Tyne, UK; takeshi.nakagawa@newcastle.ac.uk ${ }^{2}$ www.suigetsu.org

Two decades of effort by three generations of researchers has contributed to the realization of the value of Lake Suigetsu's varved sediments to Quaternary science.

ake Suigetsu has a long history Lin Quaternary research. In 1991, a group of Japanese researchers, led by Prof. Yoshinori Yasuda of the International Research Center for Japanese Studies (IRCJS, Japan), recovered a couple of $>10$ m long piston cores from the lake and found that the lower parts of those cores were annually laminated (varved; Fig. 1). This marked the initiation of varve studies in Japan.

Two years later (1993), the same group conducted deep drilling of Lake Suigetsu and recovered a $>73 \mathrm{~m}$ long sediment core that reached bedrock. The top ca. $40 \mathrm{~m}$ of the core was quasicontinuously varved. The earliest important scientific outcomes from this long core (SG93) were delivered by Hiroyuki Kitagawa of IRCJS and Hans van der Plicht of Groningen University (the Netherlands). They extended terrestrial radiocarbon calibration close to the limit of the method ( $\mathrm{ca} .50 \mathrm{ka}$ ) by combining varve counting and $>300$ radiocarbon measurements obtained on terrestrial leaf fossils extracted from the core (Kitagawa and van der Plicht 1998a, 1998b, 2000). Since then the lake has acquired international recognition as an environmental archive of high value (it is sometimes even referred to as "The Japanese Lake") - especially by the radiocarbon community.

The internationally ratified IntCal radiocarbon calibration model for deriving calendar ages from radiocarbon data was first proposed in 1998 (Stuiver et al. 1998) and subsequently updated in 2004 and 2009 (Reimer et al. 2004, 2009). Ideally, radiocarbon calibration should be based on independentlydated terrestrial materials such as tree rings and terrestrial plant remains in lacustrine sediments (speleothem records, although terrestrial, require correction for unknown dead carbon fractions). However, the present IntCal model relies on marine archives, such as corals and Cariaco Basin sediments for the period beyond the continuous tree-ring record. Even in the latest version, the tree-ring record reaches only back to 12,550 cal. BP. This still leaves three quarters of the radiocarbon calibration based on marine data, including the assumption of a constant offset from the atmospheric radiocarbon concentration, known as the marine reservoir age. As a terrestrial archive, the Lake Suigetsu radiocarbon data are free from the marine reservoir age problem. However, the dataset has never become an integral part of IntCal, mainly because of a significant deviation of the Suigetsu ${ }^{14} \mathrm{C}$ data from the marine-based records, which cast doubt on the SG93 varve chronology.

Early outputs from the SG93 core also included reconstruction and dating of paleoclimatic events. Based on the varve chronology and pollen analysis of $>400$ samples from the late glacial part of the core (ca. 16-10 ka), Nakagawa et al. $(2003,2005)$ argued that the late glacial climate in Japan exhibited similar millennial-scale oscillations to the North Atlantic but with centennial-scale offsets in timing. However, this was not widely accepted by the community, partly because of the issues with the SG93 varve chronology, and also because it was not in good agreement with East Asian speleothem records that were precisely U-Th dated (Wang et al. 2001; Shen et al. 2010).

More recently, Staff et al. (2010) re-analyzed the SG93 radiocarbon dataset by Bayesian statistical modeling techniques (Bronk Ramsey 2008, 2009) using IntCal09 as the matching target. This revealed that the gaps between core segments of SG93 were larger than initially supposed, and that the

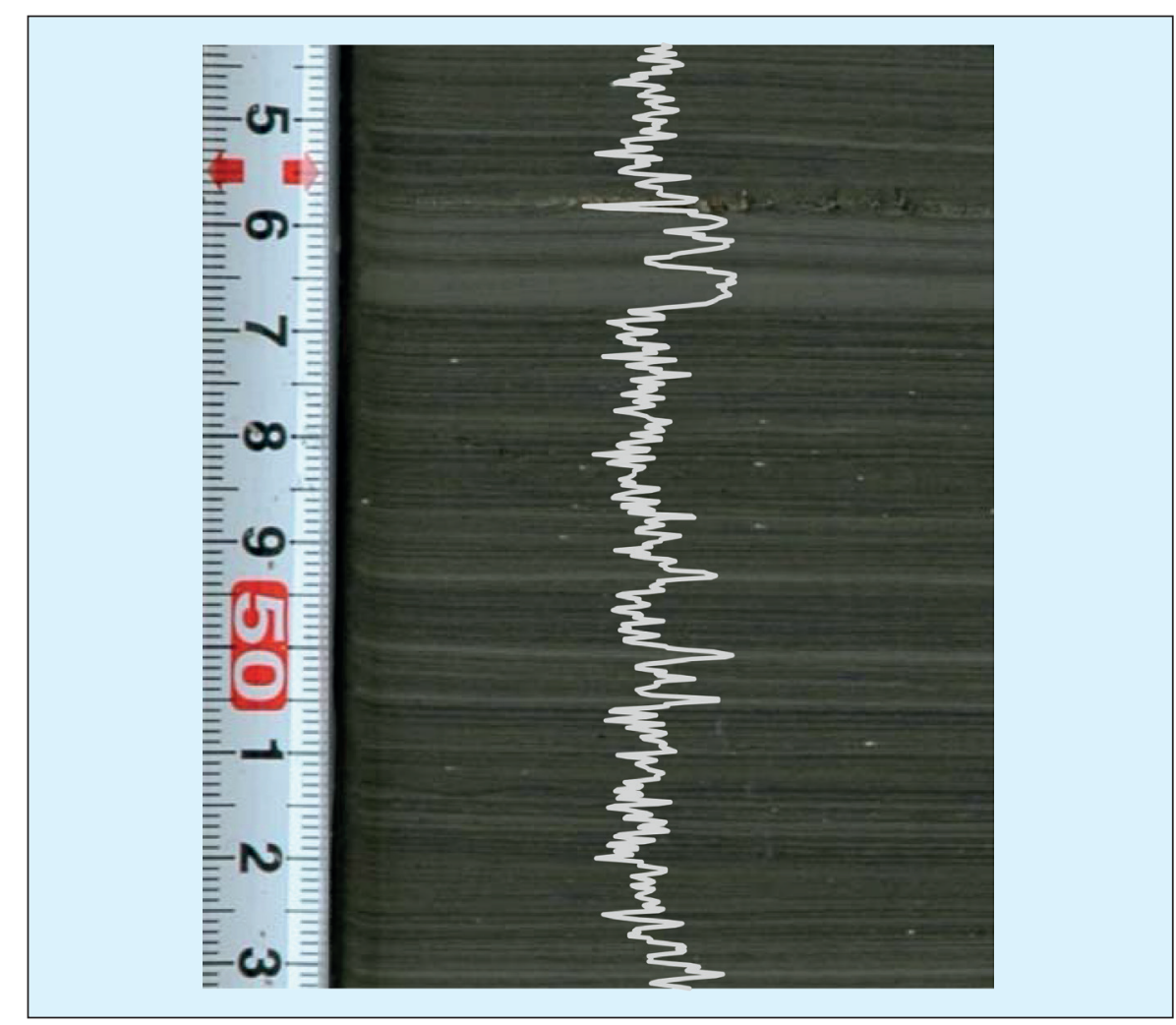

Figure 1: Varved sediments of Lake Suigetsu, Honshu Island, Japan. The curve shows relative gray scale values as measured on the displayed image. 


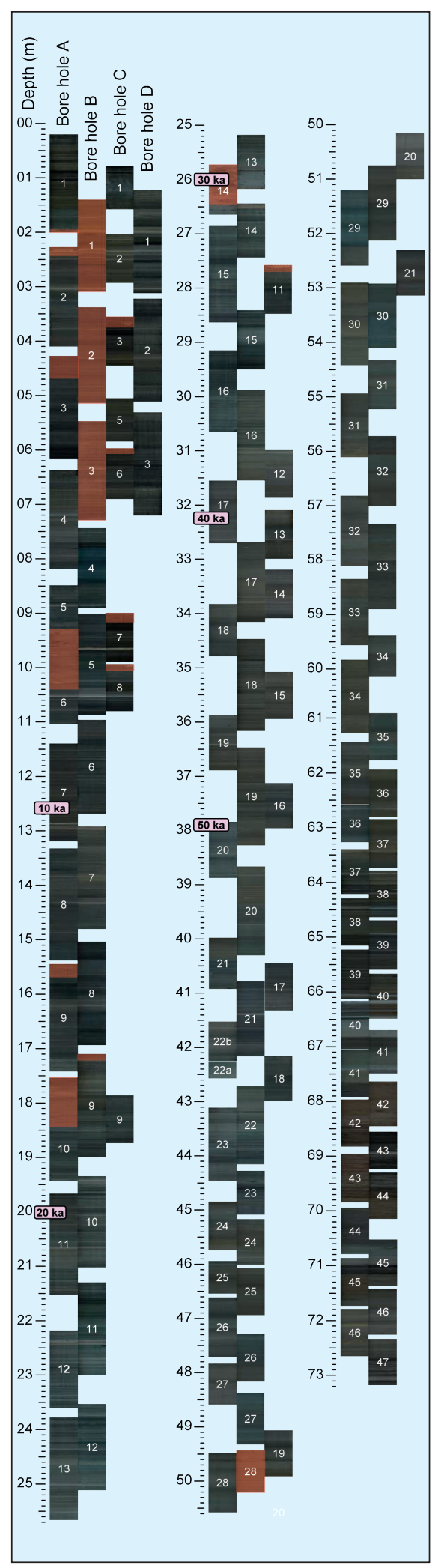

Figure 2: Photographic litho-stratigraphy of the SG06 core (modified after Nakagawa et al. 2012). Red shades show disturbed sediment sections. The coring team consisted of people from Newcastle University (UK), University of Tokyo, Osaka City University, Chiba University of Commerce, Naruto University of Education, Kyoto University (Japan), GeoForschungsZentrum Potsdam (Germany), and Royal Holloway University of London (UK). estimated gaps were roughly sufficient to account for the departure of the SG93 radiocarbon data from marine curves. In other words, it convincingly demonstrated that (i) the SG93 varve chronology was generally too young, and (ii) the main source of error was the discontinuity of the core rather than varve counting inaccuracy. This meant that the potential scientific value of the Lake Suigetsu varved sediment remained very high, if sampled in the form of continuous sediment cores.

\section{Suigetsu returns!}

Phase Two of the Lake Suigetsu study began in 2006, when funding was secured from the Natural Environment Research Council (NERC), UK to recore the lake. An international team, consisting of researchers from the UK, Japan, and Germany, recovered a new master core (SG06) in summer 2006 from four parallel bore holes with sufficient overlap to provide a $100 \%$ continuous, $73.2 \mathrm{~m}$ long sediment profile covering the past ca. $150 \mathrm{ka}$ (Nakagawa et al. 2012; Fig. 2). Building on the success of the SG06 coring, a further extended research group obtained additional funding from NERC and the German Research Foundation, along with other internal support from UK and Japanese institutions to analyze the core in detail.

Varve counting is the crucial part of the whole project. We therefore employed both conventional counting by thin-section microscopy, and ultrahigh resolution scanning $(60 \mu \mathrm{m}$ stepping) using an Itrax $^{\mathrm{TM}} \mathrm{X}$-radiograph and XRF scanner (Marshall et al. 2012; Francus et al. 2009). The two parallel counting results were merged into a single age-depth model using newly developed statistical methods (Schlolaut et al. 2012; Marshall et al. 2012). The merged varve chronology of the SG06 core has already been established down to ca. $30 \mathrm{ka}$. Soon, it will be extended beyond the radiocarbon limit (>50 ka).

More than 600 radiocarbon measurements were made on terrestrial tree leaf fossils, manually extracted from SG06. The distribution of the radiocarbon dates shows good agreement with the terrestrial part of the IntCal09 model (0-12,550 cal. BP) supporting the continuity of the sediment and the accuracy of the merged varve chronology (Staff et al. 2011; Marshall et al. in press).
A notable tephra horizon (the 'SG061288 ', or 'U-Oki' tephra) provides an important marker layer in the early Holocene part of the SG06 core, which has been precisely dated by numerous radiocarbon dates and Bayesian wiggle matching to the terrestrial part of the IntCal09 calibration model (Staff et al. 2011; Bronk Ramsey 2009). Recently we conducted Ar/Ar dating of 34 sanidine crystals extracted from the proximal deposits of this tephra, and attained excellent $\mathrm{Ar} / \mathrm{Ar}$ age determination with errors $<3 \%$, in spite of operating close to the younger limit of the Ar/Ar technique (Smith et al. 2011). This suggests that we will be able to apply the same method for the deeper part of the core, reduce the cumulative counting error of the SG06 varve chronology, and significantly improve the accuracy of the terrestrial radiocarbon calibration dataset beyond the tree ring limit.

The Lake Suigetsu 2006 project has also yielded a range of paleoclimatological data that are almost ready to be published. Most of them are still waiting for the independent chronology to be finalized. However, Kossler et al. (2011) have already reported decadal to sub-decadal scale sequential changes in diatom flora, sedimentary structure and local vegetation during the Lateglacial transitions. Papers on event timings based on high-resolution pollen, biomarker, and XRF results will follow shortly.

\section{Summary}

Our new Lake Suigetsu project aims to (i) provide a key dataset for more reliable terrestrial radiocarbon calibration over the whole range of the method, and (ii) provide a reference record for the East Asian Monsoon region. After two decades of effort by three generations of researchers to pave the runway, research on the Lake Suigetsu varved sediment record is now finally taking off.

\section{Selected references}

Full reference list online under:

http://www.pages-igbp.org/products/newsletters/ref2012_2.pdf

Kitagawa H, van der Plicht J (1998a) Science 279: 1187-1190 Nakagawa T et al. (2012) Quaternary Science Reviews 36: 164-176 Reimer PJ et al. (2009) Radiocarbon 51: 1111-1150 Smith VC et al. (2011) Quaternary Science Reviews 30: 2845-2850 Staff RA et al. (2011) Radiocarbon 53: 511-528 